\title{
CAINDO NA REAL: NOTAS SOBRE 0 REALISMO INUSITADO EM BECKETT E EURÍPIDES
}

Fáblo de Souza Andrade

Universidade de São Paulo

\section{Resumo}

Que "realismo" se esconde sob um teatro dito "do absurdo" como o beckettiano? O que pode significar a mesma ideia relacionada ao mundo da tragédia euripidana? Comparando a recepção crítica de Dias felizes e Electra, este ensaio busca explorar um conceito cuja utilidade rivaliza apenas com sua labilidade.

Abstract

What kind of "realism" might be found in a dramatic work known worldwide as "absurd"? What should we take for "realism" having Euripides' tragedies in mind? Comparing Happy days' and Electra's critical reception, this paper explores a manifolded concept, which has proved itself as useful as deceitful.

\author{
Palavras-chave \\ Beckett; \\ Eurípides; Dias \\ felizes; Electra; \\ realismo; \\ tragicomédia e \\ comitragédia.
}

\footnotetext{
Keywords

Beckett;

Euripides;

Happy days;

Electra;

realism;

tragicomedy

and

comitragedy.
} 


\author{
"Eu suava em bicas. (Pausa.) Antigamente. \\ (Pausa.) Agora, quase nada. (Pausa.) O calor \\ aumentou. (Pausa.) A transpiração diminuiu. (Pausa.) \\ É isso que eu acho maravilhoso. (Pausa.) Como \\ o homem se adapta. (Pausa.) Às condições que mudam." \\ (Samuel Beckett, Dias felizes)
}

inculada na origem à experimentação e à ruptura de gêneros típicas do alto modernismo, tida em sua vertente dramática como alicerce maior de um "teatro do absurdo", a obra de Samuel Beckett (1906-1989) é erradamente relegada pelo automatismo crítico às regiões antípodas do realismo, tradição contra a qual seus romances e peças teriam se imposto. Um dos nós da questão está na elasticidade do conceito, ora remetendo a um período preciso da história literária pósromântica, ora a um processo de longa duração, a progressiva invasão da alta literatura ocidental pela representação séria do cotidiano humilde, pedra de toque da crítica de Erich Auerbach. Nenhum desses dois aspectos mencionados do realismo é indiferente ou dispensável à compreensão e à apreciação da obra beckettiana. Por um lado, não há Molloy sem Rastignac, nem Winnie sem Nora. Beckett chega ao cabo de um ciclo; a impossibilidade de ação e a razão tortuosa que amarram seus solitários protagonistas são expressão do beco sem saída a que se viu confinado o sujeito burguês na esteira da alienação contemporânea. Por outro, há uma dimensão mimética em sua obra construída a partir de farrapos de linguagem e restos de erudição e cultura letrada, a mimese em segundo grau de que nos fala Adorno, que faz pensar na culminância do tratamento sério de aspectos prosaicos da realidade que Auerbach estudou. ${ }^{1}$

Para pensar esse realismo a contrapelo, por terra e aterrador, que se esconde por trás da estranheza de suas personagens - ora vagando a esmo, ora imobilizadas à força, solitárias em meio a uma babel interior de vozes alheias -, é preciso, contudo, focalizá-lo e exorcizar alguns fantasmas críticos. Penso que nem as leituras essencialistas, que ignoram a força da impregnação histórica de seu material estético, nem as que, no polo oposto, se baseiam em um literalismo historicista, atribuindo peso explicativo a determinadas vivências biográficas ou acontecimentos

${ }^{1}$ Theodor Adorno, "Versuch, das Endspiel zu verstehen", in Noten zur Literatur, Frankfurt am Main, Suhrkamp, 1981. 
históricos singulares, nos levam muito longe. Um bom ponto de partida, ainda que nada novo, seria levar em conta o quanto o realismo em Beckett se afirmou em polêmica modernista contra o XIX, "século sério", de que nos fala Franco Moretti, em que o romance e o drama burguês alcançaram seu apogeu. Com acerto, Carla Locatelli mostra como os recursos técnicos de sua prosa inicial, compreendendo o volume de contos More pricks than kicks e o romance Murphy, jogavam parodicamente com os fundamentos do realismo formal e só se deixam compreender no diálogo intertextual com os pontos altos dessa tradição, de Sterne a Balzac. O salto estranhador veio com a trilogia romanesca parisiense do pós-guerra (Molloy, Malone morre e $O$ inominável) em que aquela ironia intertextual cedeu espaço a um novo patamar de corrosão das convenções narrativas, agora interno ao texto, produzindo obras de máxima tensão e no limiar da ruptura formal, mas tramadas a partir de matéria prosaica e cotidiana. ${ }^{2}$

De passagem, é preciso notar que a percepção da insuficiência da forma romance tal como amadurecida pelo realismo formal não é produto de uma inteligência aberrante ou singularmente genial, mas sintoma disseminado do esgotamento de um modelo (o que vale também para o naturalismo no teatro). A disputa em torno do como interpretar essa crise de gêneros - uma involução estética ou um alargamento do realismo que permite sua sobrevivência - é o fulcro de conhecida polêmica entre Adorno e Lukács, na qual a obra de Beckett figura como um dos pomos da discórdia. ${ }^{3}$

Não por gosto de pisar em ovos, mas pelo curioso paralelo na recepção crítica, proponho-me a rever os termos da equação do realismo em Beckett à luz de outra obra que, mesmo fora de qualquer figurino realista estrito e apesar do risco evidente de anacronismo, tem sido assim qualificada repetidas vezes. Fruto da produção madura de Eurípides, o "mais trágico dos trágicos" segundo Aristóteles, Electra contrasta enormemente com o tratamento que a vingança dos filhos de Agamêmnon contra os algozes do pai - Clitemnestra, a mãe, cabeça do assassinato, e Egisto, seu cúmplice e amante, usurpador do trono - recebeu nas peças de Ésquilo (Coéforas) e Sófocles (uma homônima Electra) dedicadas ao mesmo mito. Essa discrepância inúmeros comentadores modernos atribuíram à presença difusa de um vago realismo na peça.

"Realista comparada a quê?" é a pergunta que fica aos leitores modernos de Eurípides e da resposta, por mais tateante que seja, também haverá algo a aprender e precisar sobre a pertinência do conceito para o estudo da obra beckettiana. Para extrair o máximo da comparação, aproximo a Electra de Eurípides a uma única peça do autor de Godot, um texto que também traz uma protagonista feminina em primeiro plano quase exclusivo. Falo da Winnie, de Dias felizes, que, presa até a cintura, depois até o pescoço, na terra crestada de uma colina, sob um

${ }^{2}$ Cf. Carla Locatelli, "Typologies of meaning in Beckett's narratives", in Unwording the world: Samuel Beckett's prose works after the Nobel prize, Philadelphia, University of Pennsylvania Press, 1990.

${ }^{3}$ Ver Georg Lukács, Significiación actual del realismo crítico, trad. Maria Teresa Toral, Mexico, Ediciones Era, 1963; e Theodor Adorno, "Erpresste Versoehnung - zu Georg Lukács: Wider den missverstanden Realismus", in Noten zur Literatur, Frankfurt am Main, Suhrkamp, 1981. 
sol a pino sem trégua, choca os espectadores pela naturalidade com que enfrenta o insólito de sua situação.

\section{Electra e a tragicomédia: raízes do realismo euripidiano}

"Nada é mais engraçado que a infelicidade."

(Samuel Beckett, Fim de partida)

Os traços perturbadores da Electra, de Eurípides, escrita provavelmente entre 420 e 413 a.C., concentram-se na primeira metade da peça, desafiando desde a abertura as convenções da tragédia ateniense, já firmemente estabelecidas àquela altura do século V. Quem primeiro nos apresenta as circunstâncias envolvendo a infelicidade de Electra, aviltada e longe do palácio, é o marido arranjado da heroína. Trata-se de um camponês, anônimo e de baixa estirpe, escolhido a dedo por Egisto para afastar a sombra de possíveis futuros rivais, herdeiros reivindicando o poder que ele obteve de maneira criminosa. Humilde, porém honesta, a fala inicial do marido defende a decisão de não consumar um casamento de fachada em respeito ao abismo social que o separa da esposa - "Sabe Afrodite que este que vos fala / jamais deixou de ser respeitador,/ jamais a deflorou! De classe baixa,/ me avexa o ultraje à filha do ricaço!". Revela também sua natureza pragmática, também preocupada em resguardar a própria reputação e deixando claro que, se necessário, desceria à troca de insultos: "Quem me chamar de frouxo por manter/ a virgem intocada na choupana,/ saiba que mede o certo com parâmetros/ torpes, os seus! Devolvo o xingamento!". ${ }^{4}$

Desde logo maculada pelos tons risíveis, se não ridículos, do monólogo inicial, lavagem pública de roupa suja doméstica, a dignidade trágica do tema da vingança de Electra e Orestes e da iminência de nova morte no seio da funesta família abalase ainda mais à primeira aparição de Electra. Equilibrando um cântaro na cabeça, disposta a buscar pessoalmente a água necessária à rotina da casa, apesar da insistência em contrário do marido, ela se mostra de uma amargura ressentida bem pouco sublime, exagerando a própria humilhação e repleta de autopiedade afetada. Comprazendo-se no papel de serva de si mesma, essa Electra lata-d'água-na-cabeça abordada por estrangeiros desconhecidos (na verdade, seu irmão Orestes e o amigo Pilades, incógnitos, vindos para resgatar a honra de seu pai) ralha estrondosamente com o marido que lhes oferece hospitalidade: como receber gente nobre em casa tão humilde? O que servir aos convivas? Que vergonha, o que dirão do como estou vestida? O gesto acolhedor deste último, por sua vez, tampouco vem sem titubeio. O camponês precisa vencer a profunda irritação que a atitude inconveniente, no limite do indecoroso, dos recém-chegados - conversando, animados, com sua mulher desacompanhada - lhe desperta.

A rusga do casal expõe seus pretextos comezinhos, estranhos à natureza do trágico, sem pejo algum. Não é piedade ou terror que o realismo doméstico dessas

${ }^{4}$ Cf. Sófocles/Eurípides, Electra(s), trad. e pref. Trajano Vieira, São Paulo, Ateliê Editorial, 2009, p. 82. 
cenas desperta. É riso. Tanto que Bernard Knox não hesita em fazer traçar a partir delas a origem da comédia moderna (muito diversa da comédia aristofânica contemporânea do auge da tragédia), fazendo de Eurípides o núncio precoce de uma linhagem que, inaugurada por Menandro, conduz de Plauto e Terêncio, passando pelos dramaturgos renascentistas, aos grandes nomes da tradição europeia do gênero, de Shakespeare a Oscar Wilde. ${ }^{5}$ Trata-se da comédia de costumes, das intrigas familiares entre pai e filho, marido e mulher, das identidades trocadas e reveladas, da superação das desavenças entre pretendentes apaixonados e pais zelosos. A ruptura do sistema de gêneros dramáticos que a novidade da Electra euripidiana força no final do século $\mathrm{V}$ ateniense - alterando decisivamente sua estrutura e procedimentos composicionais, como atesta a redução da importância antes central do coro - é que torna o cotejo com Dias felizes de tanto interesse. Também no contexto moderno estamos às voltas com um alargamento de possibilidades expressivas que, em grande parte, radica nessa combinação inédita de recursos trágicos e cômicos, reordenação das convenções formais dos gêneros puros em momento de crise e esgotamento de modelos bem estabelecidos. ${ }^{6}$

Como no caso de Beckett, campos muito diversos são recobertos pelo emprego intuitivo, indiscriminado e generalizado do termo "realismo" entre os comentadores da Electra euripidiana. Em recente balanço do estado atual da questão, Barbara Goff agrupa seu uso mais recorrente em quatro grandes categorias. ${ }^{7}$ Primeiro, há os que como H. D. Kitto e Friedrich Solmsen identificam no desenho da personagem o dedo do realismo psicológico do autor, grande conhecedor da psiquê feminina. Afastando-se de Ésquilo e Sófocles, Eurípides teria feito da sua Electra algo além de uma figura abstrata, mero suporte da ação e da força do mito, aproximando os contornos de seu ressentimento de paixões comuns, de gente como a gente. No entanto, como observa Goff, ainda que abandonar o modelo trágico anterior represente de fato um passo na direção do que entendemos por realismo, a natureza extremada das falhas e das fraquezas da Electra euripidiana são idiossincráticas, assumem dimensões monstruosas, extraordinárias, impossíveis de atribuir à gente comum.

Em segundo lugar, Goff lembra os helenistas que enfatizam a invasão da peça por uma "atmosfera geral de domesticidade", expressão também de Kitto, destacando no cenário simples e figurino modesto a materialidade das coisas do dia a dia, trazendo para o primeiro plano os cântaros, a comida ou o traje simples, os "trapos" que vestem e envergonham a protagonista. O mesmo Bernard Knox assinala o quanto essa ênfase nos objetos ignóbeis e na comilança parece deslocada no território do trágico, lembrando antes a preocupação dominante de personagens da comédia ou

${ }^{5}$ Bernard Knox, "Euripidean comedy", in Word and action: essays on the Ancient Theater, Baltimor, London, The Johns Hopkins University Press, 1979.

${ }^{6}$ A boa tradução recente de Trajano Vieira apanha bem esse traço, vertendo uma fala do marido, no calor da discussão com Electra, por um coloquialíssimo "Será o Benedito?" (Sófocles/ Eurípides, Electra(s), op. cit., p.83, síntese correta do tom ambíguo da personagem, obreiro digno, mas matuto, sério, mas risível.

${ }^{7}$ Barbara Goff, "Try to make it real compared to what? Euripides' Electra and the play of genres", in M. Cropp, Kevin Lee, D. Sansone (ed.) Euripides and tragic theatre in the late fifth century, Illinois, Illinois Classical Studies, 2000. 
do drama satírico (como o Ciclope, do próprio Eurípides), ainda que o tom cômico assuma na Electra uma nova função: a de confronto com a tradição mítica por trás do trágico, introduzindo na peça uma "dicotomia entre o passado heróico e majestoso do mito e o presente democrático, nada glamoroso da realidade". ${ }^{8}$

Afastando-se do modelo homérico de heroísmo, predominante na Ilíada, o Eurípides maduro teria passado a beber mais no mundo da tradição familiar e doméstica, que em Homero encontra seu lugar na Odisseia. Na peça em questão, o preâmbulo leve, contudo, não impede que os horrores do desfecho se confirmem (Electra e Orestes levam a cabo o que previa o mito e tiram a vida de Clitemnestra), mas cria uma nova zona de complexidade moral, em que motivos fúteis e banais - como o esnobismo ofendido da protagonista - e expedientes baixos - como atrair a mãe para a morte dizendo-se recém-parida e necessitada de ajuda - disputam a primazia com o que nas tragédias anteriores dedicadas ao tema correspondia a um desejo legítimo de reparação.

Autores como Winnington-Ingram e George Gellie, por sua vez, atribuem a nota identificada como realista no Eurípides tardio a uma terceira razão: um ceticismo crescente da plateia ateniense do fim do século $\mathrm{V}$, formada por espectadores médios que, no contexto da ascensão do sofismo e da filosofia, passavam a exigir do dramaturgo clareza, lógica e razão que se aplicavam ao contexto cotidiano. De fato, a cena do reconhecimento entre os irmãos na Electra traz uma paródia saborosa da passagem análoga nas Coéforas, de Ésquilo, em que a lógica implacável da protagonista euripidiana derruba, um a um, os mesmos argumentos que na peça de Ésquilo a convencem da volta do irmão ausente e conferem eficácia poética à reunião da memória remota da convivência à urgência presente dos planos de vingança.

Em Ésquilo, libando junto ao túmulo do pai, Electra encontra a oferta de mechas de cabelo que lembram o seu, pegadas que combinam com as suas e, por fim, um estranho portando uma veste enfeitada por um bordado antigo saído de suas mãos, a quem associa o cabelo e as pegadas. Os sinais tem sobre ela efeito de revelação divina, levando-a à certeza aliviada da volta do irmão. Já em Eurípides, quando um ancião, amigo de seu pai, coloca-a frente a frente com os mesmos elementos, a moça passa longe de aceitá-los. Ao contrário, ridiculariza-os tomada por irrecusável bom senso pedestre: quanto aos cabelos, mostra que tom idêntico não é exclusivo a parentes e, além disso, "que relação existe entre as madeixas/ de um nobre desportista e as melenas/ de uma donzela que as escova sempre?"; desconfia da existência em si das pegadas - "como o pé se imprime em terreno pedregoso?" - e descarta a possibilidade da semelhança de forma entre os pés de irmãos, "pois homens calçam mais"; por fim, lembra que Orestes partiu menino e, mesmo que então levasse vestes bordadas por ela, seria impossível que, homem agora, ainda as trouxesse vestidas, a menos que as roupas "crescessem com o corpo". ${ }^{9}$ Note-se que essa dimensão paródica e metateatral da peça, presente desde o primeiro episódio (o cântaro de água para uso doméstico rebaixa o jarro usado

\footnotetext{
${ }^{8}$ Arnott apud Goff, "Try to make it real compared to what? Euripides' Electra and the play of genres”, op. cit., p. 97.

${ }^{9}$ Sófocles/Eurípides, Electra(s), op. cit, p. 100.
} 
durante as libações nas Coéforas), também perturba a suspensão da descrença associada ao trágico.

A quarta vertente crítica, segundo Goff, entende o realismo em Eurípides como expressão quase imediata do contexto histórico grego contemporâneo. O resultado abala a imagem corrente do dramaturgo como um subversor da ordem e reforça a presença de valores socialmente normais em sua obra. Passagens da Electra que a outros leitores pareceram esdrúxulas, expressão de uma autocomiseração incompatível com a dignidade de uma heroína trágica, seriam compreensíveis à luz de comportamentos convencionais disseminados na sociedade grega (o exagero da dor como sinal de luto, por exemplo).

Ainda que repleto de armadilhas, do anacronismo psicologizante ao historicismo mecanicista, o quadro resumido é imensamente sugestivo, tanto para os interessados em sua obra quanto para os que investigam o conceito do realismo. Bem pesada a tensão entre desfecho trágico e os recursos cômicos e paródicos da abertura, a invasão do domínio trágico pela esfera doméstica e a diferença de classes, a ênfase na materialidade simples dos objetos cênicos e da vida humana, a submissão da verdade poética do mito ao tribunal da lógica eficaz e das razões práticas cotidianas, parece que o melhor sinal da impregnação da obra de Eurípides pela história e a realidade contemporânea está numa transformação essencial da forma trágica, acolhendo em proporção inédita elementos cômicos e praticamente fundando uma nova tradição, a da tragicomédia, vertente longeva e aberta à apreensão estética do material cotidiano.

\section{Dias felizes e a comitragédia: Beckett e o realismo contracorrente}

"Nada é mais grotesco que o trágico."

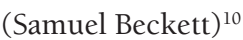

As variáveis críticas que envolvem a questão do realismo beckettiano são curiosamente análogas e de idêntica complexidade às que rondam o Eurípides da primeira parte da Electra, mas também da Helena e da Ifigênia em Tauris. Se o drama maduro euripidiano inaugura uma nova combinação de trágico e cômico, um gênero eivado de elementos temáticos e formais que modernamente reputamos realista, o teatro e a ficção do autor de Esperando Godot vêm na esteira de um longo desenvolvimento orgânico dessa tradição. Em Eurípides, estranha-se o despertar de um certo "realismo" ainda desconhecido; em Beckett, sua sobrevivência pouco reconhecível à custa de uma superação das convenções enrijecidas. Em comum, ambos dividem o contexto de crises no sistema de gêneros literários de seu tempo.

Os fundamentos do controverso "realismo" euripidiano na Electra têm encontrado justificativa em quatro principais linhas, mais ou menos produtivas critica-

\footnotetext{
${ }^{10}$ Em carta a Roger Blin, de 9 de janeiro de 1953, Beckett ressalta a importância da cena de Esperando Godot em que, procurando algo para se enforcar, Estragon desamarra a corda que lhe serve de cinto e suas calças caem até os calcanhares, deixando-o seminu em cena aberta: "the spirit of the play, to the extent to which it has one, is that nothing is more grotesque than the tragic" (cf. a biografia de Deirdre Bair, Samuel Beckett, New York, Simon and Schuster, 1990).
} 
mente. É mais que possível transformá-las em hipóteses de leitura da dramaturgia beckettiana na aposta razoável de que o resultado também jogue luz sobre uma dimensão realista da obra do irlandês escamoteada pelo rótulo corrente e inadequado de autor "do absurdo".

Concebida e levada aos palcos pela primeira vez em 1961, Dias felizes apresenta em dois atos os monólogos de Winnie, uma mulher vaidosa, de meia-idade, presa a um casamento também envelhecido. A banalidade otimista e corriqueira de suas falas contrasta flagrantemente com a situação insólita e desesperadora em que a vemos apanhada. Ao seu redor, em um passado impreciso, a terra árida de um deserto desabitado abriu-se em armadilha, mantendo-a enterrada, primeiro até a cintura, depois até o pescoço, ao longo de toda ação. Tudo que lhe resta é falar a esmo, entreouvida às vezes pelo marido indiferente, ou dedicar-se aos cuidados femininos com a toalete, distraindo-se com o repetitivo inventário do conteúdo da bolsa que a acompanha. Na sua vizinhança, as leis da natureza parecem ter sido revogadas. ${ }^{11}$ Winnie alterna períodos de vigília e sono segundo os caprichos insondáveis de uma estridente campainha que marca - aleatória, mas imperativa - as horas de despertar e de dormir, sempre sob o brilho de um sol abrasador. Vive sob a angústia da travessia das horas despertas, torturada pela luz ofuscante e o calor opressivo, contando apenas com o alívio fugaz e ocasional das lembranças esparsas, restos de um passado fugidio, tão feliz quanto remoto.

Da mesma forma que a plausibilidade psicológica atribuída às razões do comportamento da Electra, sobrepondo à inelutabilidade do mito a economia do ressentimento e do orgulho ofendidos, não convence plenamente em Eurípides, a Winnie de Dias felizes tampouco se ajusta à receita de construção de um perfil psicológico complexo e convincente em seu confronto otimista com o meio hostil. A oscilação entre uma consciência possível do horror cabal de seu estado presente, temida e evitada a todo custo, e o recurso diversionista dos rituais de fuga, os jogos com palavras e coisas ao seu dispor, não se explicam a partir de um núcleo pregresso de experiência biográfica. Nem traumas específicos, nem papéis sociais típicos resolvem a complexidade da personagem.

Winnie vive uma temporalidade própria, mutilada, que não mais permite o desdobramento de uma sucessão de encontros e choques circunstanciados com as pessoas e com o mundo. O que nela se entrevê é um mundo individual feito de retalhos, o colapso da noção de subjetividade burguesa que na linguagem beckettiana se concretiza por meio de procedimentos dramáticos inesperados. É o caso da figura da repetição, estruturalmente presente em vários níveis da peça, encarnando o tempo da má infinitude, infernal, e introduzindo um intervalo entre os sentidos de gestos e falas. Animados em restos mínimos de ação desconexa e razão

\footnotetext{
11 "Você acha que a terra perdeu a atmosfera, Willie? (Pausa.) Acha, Willie? (Pausa.) Não tem uma opinião a respeito? (Pausa.) Tudo bem, é a sua cara, você nunca teve opinião sobre nada. (Pausa.) Compreensível. (Pausa.) Muito. (Pausa.) O globo terrestre. (Pausa.) Às vezes me pergunto. (Pausa.) Talvez não completamente. (Pausa.) De tudo fica um resto. (Pausa.) De tudo. (Pausa.) Alguns restos. (Pausa.) Se a razão faltasse. (Pausa.) O que não acontecerá, é claro. (Pausa.) Não de fato. (Pausa.) Não a minha. (Sorri.) Não agora. (Sorriso mais largo). Não não (cf. B. Beckett, Dias felizes, trad. Fábio de Souza Andrade, São Paulo, CosacNaify, no prelo).
} 
improdutiva, a representação dos vestígios de uma individualidade complexa, fato de teatro mais que caso clínico, ganha aqui o palco.

Em Dias felizes, há também um arremedo moderno da demanda das plateias euripidianas, movidas pela onda sofista, por uma ação que respeitasse a lógica pedestre que orienta o comportamento empírico dos homens no mundo cotidiano. Perdida em suas lembranças, Winnie narra a história de um casal de passantes, os Shower ou Cooker, derradeiras testemunhas casuais de sua vida aprisionada. Seu relato reproduz textualmente, de memória, as falas dos dois que demonstram sem margem de dúvida o empenho do homem na busca por um significado prático, na impossibilidade de um metafísico, para o espetáculo esdrúxulo que ela proporciona:

Bem, de qualquer modo - este sujeito, o Shower - ou Cooker - tanto faz - e a mulher - de mãos dadas - cada um com uma sacola - destas grandes, pardas, de supermercado - plantados lá, me olhando - até que o homem, Shower - ou Cooker - termina em "er" - tenho certeza diz: O que ela está fazendo? - O que ela está querendo? Enterrada até as tetas nesta terra estrumada - era um casca-grossa, o tipo - aí ele diz: O que significa isso? - O que será que ela pensa que isso significa? - e patati, patatá - muito mais coisa do tipo - a bobageira de sempre - e ele diz: Você está ouvindo? - e ela diz: Estou, Deus queira - e ele diz: O que significa isso de Deus queira? (Para de lixar, levanta a cabeça, olha para a frente.) E você, ela diz, o que acha que você significa? Só porque continua plantado nestes dois pés chatos, com esta mochila cheia de merda enlatada e trocas de cuecas, me arrastando, para cima e para baixo, neste deserto fodido, uma megera escandalosa, companheira à altura - (com violência súbita) - largue a minha mão e caia fora, ela diz, pelo amor de Deus, caia fora! (Pausa. Volta a lixar.) Por que ele não a desenterra? ele diz - se referindo a você, meu anjo - De que ela lhe serve assim? - De que ele lhe serve assim? - e por aí afora - as tolices de sempre - Isto! ela diz, por Deus, tenha coração - Desenterre-a, ele diz, desenterre-a, do jeito que está, ela não faz sentido - Desenterrá-la com o que?, ela diz - Eu a desenterraria com minhas próprias mãos, ele diz - acho que eram marido e - mulher. (Lixa em silêncio.) Em seguida, eles vão embora - de mãos dadas - com as sacolas - sumindo - depois sumidos - os últimos seres humanos - perdidos por estes lados. (Acaba a mão direita, examina-a, deposita a lixa, olha fixamente para a frente.) Coisa estranha, numa hora destas, lembrar de coisas assim. (Pausa.) Estranha? (Pausa.) Não, aqui tudo é estranho. (Pausa.) Sou grata por isto, em todo caso. (Voz entrecortada.) Muito grata. ${ }^{12}$

O episódio escancara o colapso dos sonhos de eficácia de uma razão finalista e instrumental, sustentáculo da (e pressuposto necessário à) forma realista clássica. Ao notar que, enterrada, aquela mulher não faz sentido algum, ou seja, não presta para nada (o que, traduzido nos termos rasteiros de sua fantasia, equivale à impossibilidade de dar curso à lubricidade do companheiro), o pragmatismo rude do passante denuncia os limites históricos dessa modalidade de razão. Sua cegueira à seriedade do impasse que testemunha também é a caricatura da inadequação de nossos instrumentos críticos no esforço interpretativo da peça. Por inércia, seguimos exigindo ao drama beckettiano uma representação compatível com o naturalismo estrito, quando é apenas a partir da erosão de suas convenções que ele ganha sua contundência incisiva.

Gesto de retórica combativa, o desprezo confesso por Balzac do leitor de primeira hora de Proust que foi Beckett não deve encobrir a nossos olhos o quanto os antirromances beckettianos da trilogia do pós-guerra parisiense (Molloy, Malone

\footnotetext{
${ }^{12}$ Beckett, Dias felizes, op. cit.
} 
morre e $\mathrm{O}$ inominável), por exemplo, se constroem em diálogo polêmico com a tradição, erodindo as convenções do realismo formal por dentro. Não tem nada da recusa abstrata do tempo presente de que foram acusados pela militância do já nada jovem Lukács, na polêmica que manteve com Adorno, incapaz de lê-los senão a partir de uma equivocada disjunção entre forma e conteúdo e decretando seu banimento como arte decadente, qualificativo primo-irmão de degenerado, selo preferido pelo nacional-socialismo.

Se uma vocação solipsista escandalosamente livre de afetos e avessa a quaisquer laços humanos caracteriza personagens marginais como Winnie, o par Estragon e Vladimir ou Molloy, desprovidas de memória ou planos, incapazes de reação transformadora e sedes de uma razão residual e falha, nem por isso deixam elas de ser típicas de seu tempo, muito ao contrário. Devemos buscar na forma nova eleita por Beckett, privilegiando o empobrecimento dos meios e a figura do paradoxo, uma revelação aguda desse impasse histórico que a transcende, conteúdo social precipitado, como queria Adorno. Nos romances, ela determina tanto o autocancelamento das estruturas narrativas, curto-circuito lógico que anula o "post hoc, propter hoc" na arquitetura geral da trama, quanto a singularidade dos torneios estilísticos beckettianos, erodindo a sintaxe da frase e apostando na repetição e nas lacunas, nas falhas da linguagem, como seus gestos expressivos por excelência. No teatro, minimiza a importância da ação, repetitiva e fragmentária, explorando a restrição voluntária do espaço, a imobilidade crônica dos protagonistas e a falência da comunicação para seguir sendo crítica.

Indissoluvelmente imbricada na forma, a realidade em ruínas que constitui a obra beckettiana dificilmente se oferecerá inteira aos que buscam sua origem na experiência biográfica transposta de eventos históricos precisos. No processo de composição de Esperando Godot, Fim de partida e Dias felizes, estudado à exaustão pela crítica, o esforço de Beckett concentrou-se na direção oposta: a do apagamento de referências diretas e identificáveis ao terror contemporâneo, ameaças que variavam da clandestinidade na França ocupada às oscilações da guerra fria. Contra aqueles que tomaram essa fala indireta como signo de um universalismo essencialista, fuga do tempo em direção a uma condição humana atemporal, ensaístas respeitáveis como Jan Kott e Marjorie Perloff procuram recusar as leituras alegóricas ancorando as peças em lastros mais determinados, capazes de conferir sentido e legibilidade a imagens desconcertantes por vocação, mas nem por isso absurdas. ${ }^{13}$

Estudos dedicados ao processo de composição das peças beckettianas demonstram como o sentido geral das revisões sucessivas dos textos foi o de cultivar potenciais ambiguidades, apagando referências a processos históricos específicos e valorizando a alusão que não nomeia diretamente, o paradoxo, a disputa entre sentidos conflitantes. Assim, se, em Esperando Godot, sobreviveu na versão final a menção cifrada aos vinhedos da família Bonnelly (onde Beckett efetivamente trabalhou quando clandestino em Roussillon, nos anos finais da Segunda Guerra),

${ }^{13}$ Jan Kott, "A note on Beckett's realism", The Tulane Drama Review, v. 10, n. 3, p. 156-59, Spring, 1966; e Marjorie Perloff, "In love with hiding: Samuel Beckett's war", The Iowa Review, v. 35, n. 1, p. 76-103, Spring, 2005. 
em Fim de partida, os indícios da escassez geral e de extinção iminente que abundam nos diálogos de Hamm, Clov, Nagg e Nell, últimos sobreviventes de uma humanidade destruída, perderam o caráter inicial, mais demarcado, com a supressão da referência à paisagem normanda devastada pela Primeira Guerra.

Também nas primeiras versões de Dias felizes, a leitura do jornal, amarelado e evidentemente vencido, com que o lacônico marido quebra excepcionalmente seu silêncio, tendia a explicar mais a desolação da paisagem. Antes, as notícias enumeravam sucessivas explosões de mísseis, causando a morte não apenas do reverendo Charles Hunter, mantida no texto final, mas de um enorme contingente: 83 padres, milhares de habitantes de Pomona, os habitantes de Man (a ilha?), onde apenas uma "faxineira de banheiro feminino" teria sido poupada. Suprimindo essas alusões cômico-grotescas a uma tecnologia de destruição de massas ativa e desgovernada, memória histórica recente e ameaça ainda no horizonte, restringindo a leitura a vagas de emprego (ironia extrema no contexto do velho casal), Beckett preferiu focar as causas e efeitos desse processo alucinado na intimidade de um casal isolado, das consciências individuais, potencializando a reverberação simbólico-alegórica do deserto inóspito que as rodeia. Se essa reescrita recusa a conversão do texto em documento histórico datado, não diminui em nada a impregnação histórica da experiência, ou impossibilidade dela, que Winnie encarna no palco. ${ }^{14}$

Kott encontra na rotina hospitalar, em especial a dos pacientes presos ao leito por longos períodos, a situação que torna compreensível a figura enigmática, "absurda", de Winnie em Dias felizes. Regulada pelos toques da campainha e pela destruição da diferença entre dia e noite, convertida numa sucessão de contínuos sobressaltos, a temporalidade singular da peça teria sua equivalência na desorientação temporal produzida pelo entra e sai ininterrupto de médicos e enfermeiras, pela estridência intermitente e sem cerimônia dos aparelhos ligados ao doente. Também o apreço reverencial de Winnie pelas coisas, tesouros preservados no resguardo da bolsa, ecoaria por sua vez a intimidade amorosa que os acamados acabariam por desenvolver com tudo aquilo que está disposto no círculo restrito ao redor do leito, alcançável pela extensão de um braço. Em síntese, Kott sustenta que a dificuldade em cumprir os rituais mínimos necessários à manutenção do corpo como suporte da vida e a destruição progressiva da autonomia, mina nos pacientes internados a inteireza psicológica, levando-os a um estado de fragilidade solitária e desamparada, incomunicável, que se ajusta como luva à rotina de Winnie.

Sedutora, a clareza do paralelo entre a experiência dos hospitalizados e o sofrimento de Winnie sob a terra também responde por seus limites. Se não devemos confundir a espera manca por Godot com uma reinvenção estética da experiência da clandestinidade dos membros da Resistência na França ocupada, reduzindo-a a documento de um processo histórico, por mais central que seja, tampouco podemos reduzir a impossibilidade de redenção de Winnie a um dos aspectos que ela contempla. A falência de seu mundo é ideológica, linguística, física e emocional, o que só torna mais excepcional e patético seu esforço de suportá-la. O impacto

${ }^{14}$ Cf. Stanley Gontarski, Beckett's Happy Days: a manuscript study, Columbus, Ohio, Ohio State University Libraries, 1977. 
revelador da visão da mulher enterrada - imagem em cena da vida travada, imobilizada à força, guarnecida pela sombra inócua de uma sombrinha modesta e a ameaça velada de um revólver - depende de sua capacidade de resistir a uma explicação cabal, a uma assimilação do que na sua estranheza é resistência à nossa indiferença cada vez maior ao horror entranhado na rotina diária, naturalizado.

\section{Estranho e familiar: o risus purus do realismo beckettiano}

Sem sombra de dúvida, o ponto em que o paralelo entre o rebuliço crítico em torno do realismo em Beckett e Eurípides mais ensina é o da confusão voluntária, cultivada por ambos até a convivência promíscua, entre recursos próprios ao trágico, como a piedade e o terror, e o recurso cômico do riso. Se a Electra euripidiana arma sua vingança grandiosa entre potes e panelas, Winnie tem por testemunhas do seu sofrimento atroz escovas de dente e postais obscenos. Como de hábito em Beckett, o drama sério deixa-se invadir em grau extremo pelo grotesco, sem rebaixar sua pretensão à seriedade, o que não escapou a alguns de seus melhores comentadores, como Hugh Kenner, Ruby Cohn ou Enoch Brater. ${ }^{15} \mathrm{Na}$ composição de Dias felizes, a um corpo que vacila e chama nossa atenção em cena para sua existência e funcionamento imperfeitos - fisiologia em primeiro plano - corresponde o exame impiedoso de uma razão tortuosa, vacilante e terminal, ainda que otimista, contra todas as apostas. Elevar as coisas ao patamar de companheiras dotadas de vontade própria, aliadas ou antagonistas mais assíduas da solitária Winnie, é o passo seguinte da lógica reificada que preside esse universo comitrágico ou tragicômico. Que a sombrinha volte no segundo ato, depois de consumida pelas chamas no primeiro, que os cacos do vidro de remédio que Winnie quebra se recomponham no mesmo prazo, eis as provas de que sob o primado da mercadoria a realidade já não se deixa ler nas linhas da superfície.

$\mathrm{Na}$ mescla de gêneros, o realismo beckettiano se distancia do modelo novecentista, sério por excelência, mas nem por isso se torna menos realista, alcançando o "risus purus", capacidade de rir na infelicidade que Watt, protagonista afásico do romance homônimo do dramaturgo irlandês, reputava a forma mais alta do riso, a única à altura do realismo estranho que nos faz falta:

Antigamente eu achava - digo, antigamente eu achava - que todas estas coisas - colocadas de volta na bolsa - se fosse cedo demais - colocadas de volta cedo demais - poderiam ser tiradas de novo - se fosse preciso - se fosse o caso - e assim por diante - indefinidamente - de volta para a bolsa - de volta para fora da bolsa - até que tocasse - a campainha. (Para a arrumação, levanta a cabeça, sorri.) Mas não. (Sorriso mais largo.) Não não. (Desfaz o sorriso. Volta à arrumação.) Pode parecer estranho - isto que... como dizer? - isto que acabo de dizer - é - (pega o revólver) - estranho - (vira-se para colocar o revólver na bolsa) - a não ser pelo fato de que - (a ponto de guardar o revólver, interrompe o movimento e vira-se de frente) - pelo fato de que - (deposita o revólver à sua direita, interrompe a arrumação, levanta a cabeça) - tudo parece estranho. (Pausa.) Muito estranho. (Pausa.) Nunca mudança nenhuma. (Pausa.) Cada vez muito mais estranho. ${ }^{16}$

${ }^{15}$ Ruby Cohn, Samuel Beckett: the comic gamut, Rutgers University Press, 1982; Hugh Kenner, The stoic comedians: Flaubert, Joyce, Beckett, University of California Press, 1975; Enoch Brater, "Beckett, Ionesco and the tradition of tragicomedy", College Literature, v. 1, n. 2, p. 113-27, Spring, 1974.

${ }^{16}$ Beckett, Dias felizes, op. cit. 